\title{
Study on electrochemical performances of sulfur-containing graphene nanosheets electrodes for lithium-sulfur cells
}

\author{
Ki-Soo Son and Seok Kim \\ School of Chemical and Biochemical Engineering, Pusan National University, Busan 609-735, Korea
}

\section{Article Info}

Received 21 January 2014

Accepted 15 March 2014

*Corresponding Author

E-mail: seokkim@pusan.ac.kr

Tel: $+82-51-510-3874$

\section{Open Access}

DOI: http://dx.doi.org/

10.5714/CL.2014.15.2.113

This is an Open Access article distributed under the terms of the Creative Commons Attribution Non-Commercial License (http://creativecommons.org/licenses/ by-nc/3.0/) which permits unrestricted non-commercial use, distribution, and reproduction in any medium, provided the original work is properly cited.

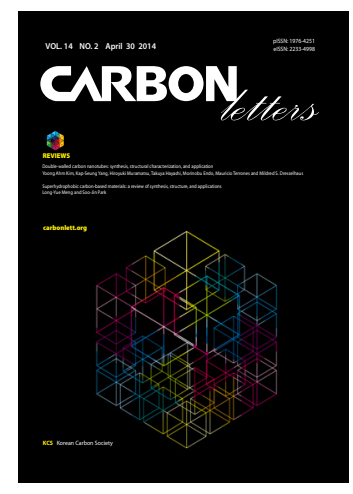

http://carbonlett.org

pISSN: 1976-4251

elSSN: 2233-4998

Copyright $\odot$ Korean Carbon Society

\begin{abstract}
Due to their morphology, electrochemical stability, and function as a conducting carbon matrix, graphene nanosheets (GNS) have been studied for their potential roles in improving the performance of sulfur cathodes. In this study, a GNS/sulfur (GNS/S) composite was prepared using the infiltration method with organic solvent. The structure, morphology and crystallinity of the composites were examined using scanning electron microscopy, transmission electron microscopy, and X-ray diffraction. The electrochemical properties were also characterized using cyclic voltammetry $(\mathrm{CV})$. The $\mathrm{CV}$ data revealed that the GNS/S composites exhibited enhanced specific-current density and $\sim 10 \%$ higher capacity, in comparison with the S-containing, activated-carbon samples. The composite electrode also showed better cycling performance for multiple charge/discharge cycles. The improvement in the capacity and cycling stability of the GNS/S composite electrode is probably related to the fact that the graphene in the composite improves conductivity and that the graphene is well dispersed in the composites.
\end{abstract}

Key words: lithium-sulfur, battery, sulfur, cathode materials

\section{Introduction}

Lithium-ion batteries have been used as power source for many electronic devices. However, due to the increased demand from huge markets such as that for electronic devices, the cathode materials are now required to provide both high-capacity and environmentally friendly energy storage. For these reasons, energy storage systems become more important than ever before. One option for next-generation batteries involves lithium-sulfur batteries (LSBs), and they have recently attracted a lot of attention due to their high theoretical capacity $\left(1675 \mathrm{mAh} \mathrm{g}^{-1}\right)$ and high specific energy $\left(2600 \mathrm{Wh} \mathrm{kg}^{-1}\right)[1,2]$. They also have the additional benefits of low cost and environmental compatibility. Despite all these advantages, LSBs have not yet been commercialize for two reasons. First is the dissolution of reactants (lithium polysulfides) into the electrolyte, and second is the low conductivity of elemental sulfur. It may be possible to develope a new electrolyte to prevent the polysulfides from dissolving, but there is no way to improve the conductivity of sulfur [3-5]. In response to these conditions, some strategies have been proposed to prevent the impact of the polysulfide shuttle effect. For instance, extensive research has been done to improve the electrical conductivity of the cathode and to trap the sulfur and polysulfides in a carbon matrix. For example, carbon matrices (i.e., porous carbons [6], carbon nanotubes [7], hollow carbon [8], carbon fibers [9], ordered mesoporous carbon [10], hierarchical porous carbon [11] and graphene nanosheets (GNS) [12] have been investigated to improve electrochemical performance by increasing the utilization of the sulfur cathode. Among these carbon materials, GNS can open new possibilities because of their high electrical conductivity, superior mechanical flexibility, high chemical and thermal stability, high surface functionality, and large surface area [13-19]. 
In this work, we prepared GNS/sulfur (GNS/S) and activated carbon/sulfur (AC/S) composites with a variety of sulfur content. In general, GNS has higher conductivity than AC composites. With this in mind, we synthesized a combination of sulfur with each carbon material, and determined what electrochemical property of the sulfur-cathode material increased in relation to the conductivity of the carbon matrix.

\section{Experimental}

\subsection{Synthesis of GNS}

Graphite oxide was synthesized from natural graphite with a modified Hummer's method [20]. Graphite, sodium nitrate and sulfuric acid were stirred; then potassium permanganate was added into the mixed composite while stirring vigorously. Next, $\mathrm{H}_{2} \mathrm{O}$ and $\mathrm{H}_{2} \mathrm{O}_{2}$ were added to the solution. The bright yellow, oxidized solution was washed with distilled water and $\mathrm{HCl}$ (43\%). Graphite oxide powder was obtained after freeze-drying. GNS was prepared by the reduction of graphene oxide (GO) with sodium borohydride $\left(\mathrm{NaBH}_{4}\right)$ as described elsewhere.

\subsection{Synthesis of GNS/S and AC/S}

GNS/S and AC/S composites were prepared by hydrothermal process, by which GNS, activated carbon (AC, MSP-20) and sulfur were dissolved in organic solvent $\left(\mathrm{CS}_{2}\right)$. At first, we prepared $20 \mathrm{~mL}$ vials. Into each vial, we then poured $1 \mathrm{~mL}$ of $\mathrm{CS}_{2}$ into a mixture of $0.1 \mathrm{~g}$ of GNS, AC, and one of $10 \mathrm{wt} \%, 15 \mathrm{wt} \%$, $20 \mathrm{wt} \%$, or $40 \mathrm{wt} \%$ of sulfur. The mixture was stirred for $2 \mathrm{~h}$ and then sonicated at $25^{\circ} \mathrm{C}$ for $1 \mathrm{~h}$. After that, the mixture was heated at $30^{\circ} \mathrm{C}$ to dry the solution. The dried GNS/S composites were heated at $155^{\circ} \mathrm{C}$ to allow the sulfur to enter the GNS.

\subsection{Morphological and physical measurement}

The structure, morphology and nanostructure of the composites were examined by scanning electron microscopy (SEM), transmission electron microscopy (TEM) and X-ray diffraction (XRD). The quantity of sulfur was measured by thermogravimetric analysis (TGA) analysis.

\subsection{Preparation of electrodes}

The electrochemical qualities were measured by cyclic voltammetry $(\mathrm{CV})$. We prepared the glassy carbon electrode (GCE) (working electrode). First, $5 \mathrm{mg}$ of active material, 0.5 $\mathrm{mL}$ of distilled water and $0.1 \mathrm{~mL}$ of Nafion were sonicated for 1 $\mathrm{h}$. Then, the GCE electrode was coated with $3 \mu \mathrm{L}$ of the mixture. Then, the coated GCE electrode was dried at $100^{\circ} \mathrm{C}$ for $30 \mathrm{~min}$. Finally, we obtained a working GCE electrode.

\subsection{Electrochemical measurement}

All electrochemical tests were done in a three electrode system. We used a platinum rod as a counter electrode and a saturated calomel electrode was used as the reference electrode. We prepared the electrolyte by adding $0.5 \mathrm{M}$ of $\mathrm{LiPF}_{6}$ as lithium salt, to dimethylformaide solution [21]. The mixture was stirred until the salt was dissolved completely.

\section{Results and Discussion}

SEM images (Figs. 1a and b) were used to study the coated sulfur on the surface of the carbonaceous materials. As shown in Fig. 1a, the GNS/S composites are uniformly distributed over a wide area. The other SEM image (Fig. 1b) is AC (MSP-20) covered with sulfur particles. Also, the image in Fig. $1 \mathrm{~b}$ confirmed that sulfur is as widely distributed on the $\mathrm{AC}$ in the GNS/S composites. The reason for this is that sulfur (which was dissolved in $\mathrm{CS}_{2}$ solvent) is easy to distribute uniformly on the GNS surface. Also, on heating, the viscosity of the sulfur melt slowly decreases, followed by a remarkable increase around $160^{\circ} \mathrm{C}$ as a result of the opening and polymerization of the $\mathrm{S}_{8}$ rings. This condition persists until near $190^{\circ} \mathrm{C}$, at which temperature sulfur starts depolymerizing and the viscosity decreases [22].

The sulfur (carried in $\mathrm{CS}_{2}$ solvent) coated onto the carbonaceous materials was better distributed because it melted by hydrothermal process at $190^{\circ} \mathrm{C}$.

Figs. $2 \mathrm{a}$ and $\mathrm{b}$, show TEM images of the GNS/S and AC/S composites. We can see the dynamically crystallized sulfur at room-temperature, and the melted sulfur at $190^{\circ} \mathrm{C}$. The TEM image in Fig. 2a shows the edge of a graphene sheet (two-dimensional) with an anchored sulfur crystal. The TEM image in Fig. $2 \mathrm{~b}$ shows the coated sulfur, which is indicated by the black area in the image.

Fig. 3 shows the XRD patterns of the GNS/S and AC/S composites. All diffraction peaks of sulfur match the standard dif-
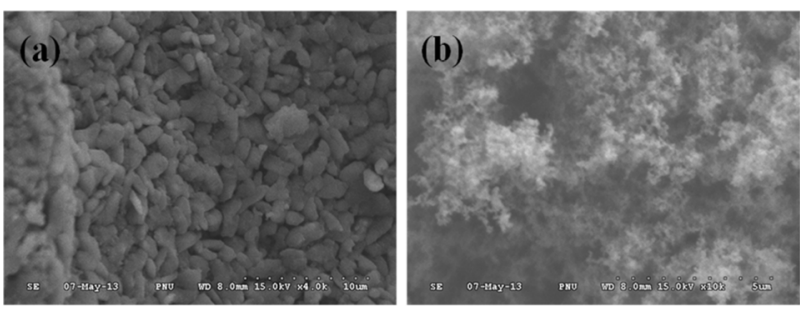

Fig. 1. Scanning electron microscopy micrographs of (a) graphene nanosheet/sulfur composite, (b) activated carbon/sulfur composite.

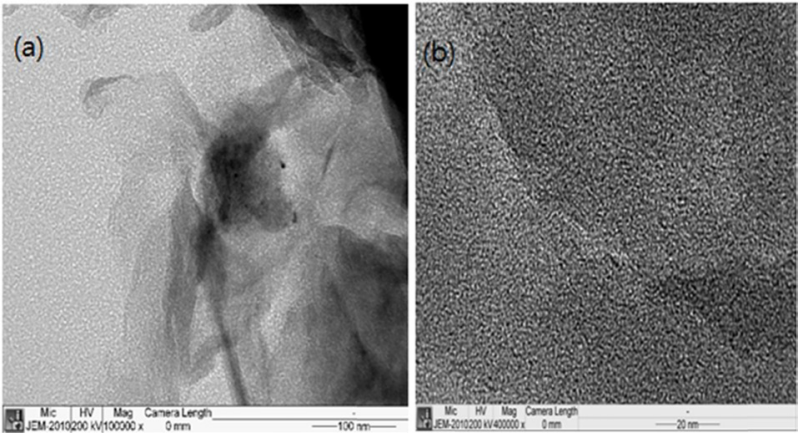

Fig. 2. Transmission electron microscopy micrographs: (a) graphenesulfur composite, (b) MSP-20-sulfur composite. 


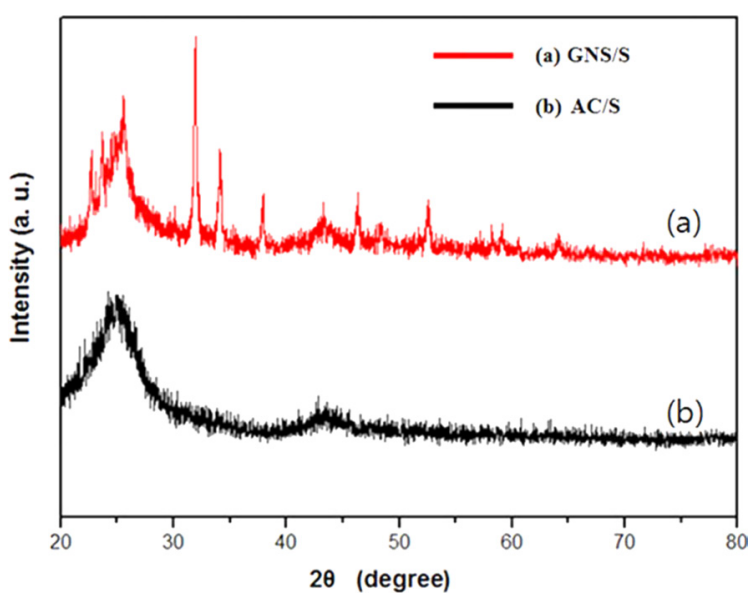

Fig. 3. X-ray diffraction pattern of activated carbon/sulfur (AC/S) and graphene nanosheet/sulfur (GNS/S) composites.

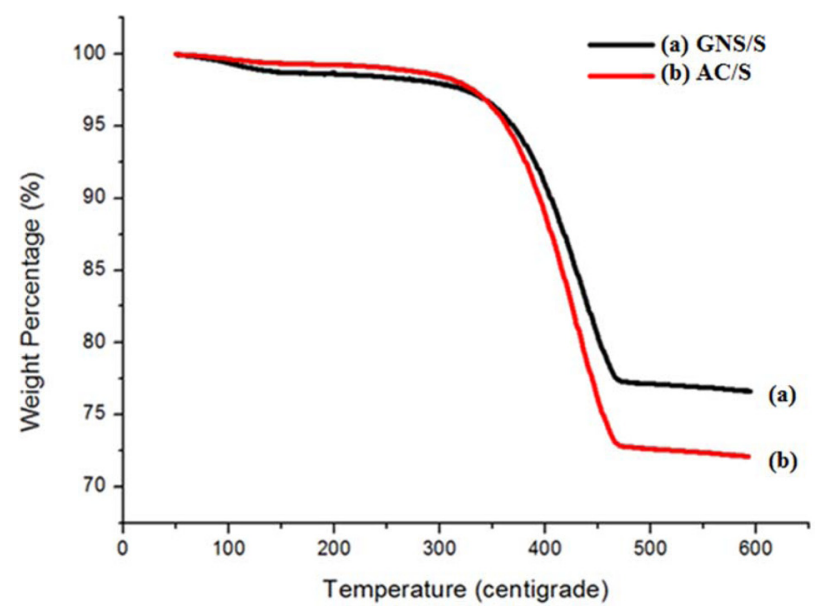

Fig. 4. Thermogravimetric analysis of activated carbon/sulfur (AC/S) and graphene nanosheet/sulfur (GNS/S) composites in nitrogen gas.

fraction lines of sulfur, which could be indexed to the orthorhombic phase with a space group of Fddd [1]. For the GNS/S and $\mathrm{AC} / \mathrm{S}$ composites, the XRD pattern consists of diffraction peaks of sulfur and a broad diffraction peak at $25^{\circ}$.

Fig. 4 demonstrates the TGA curve of the GNS/S and AC/S composites. When heated from 0 to $600^{\circ} \mathrm{C}$, at a rate of $10^{\circ} \mathrm{C} /$ min, the evaporation rate of the sulfur from the GNS/S and AC/S composites can be used as indirect evidence to locate the sulfur loaded onto the GNS and AC. As can be seen from Fig. 4, the $\mathrm{AC} / \mathrm{S}$ and $\mathrm{GNS} / \mathrm{S}$ composites started to oxidize at $350^{\circ} \mathrm{C}$ and $250^{\circ} \mathrm{C}$, respectively. After that, second mass change occurred at $450^{\circ} \mathrm{C}$ and $350^{\circ} \mathrm{C}$.

Fig. 5 shows the $\mathrm{CV}$ curves of the GNS/S- and AC/S-composite electrodes in the three-electrode system. We measured from $-1.5 \mathrm{~V}$ to $1.0 \mathrm{~V}$, at $10 \mathrm{mV} / \mathrm{S}$, to check the oxidation and reduction peaks. We carried out tests for 50 cycles. In the initial cycle, both $\mathrm{AC} / \mathrm{S}$ and GNS/S composites did not show properties of CV.

The composites show oxidation and reduction peaks after achieving electrode stability. For the $\mathrm{CV}$ of the $\mathrm{AC} / \mathrm{S}$ composite,

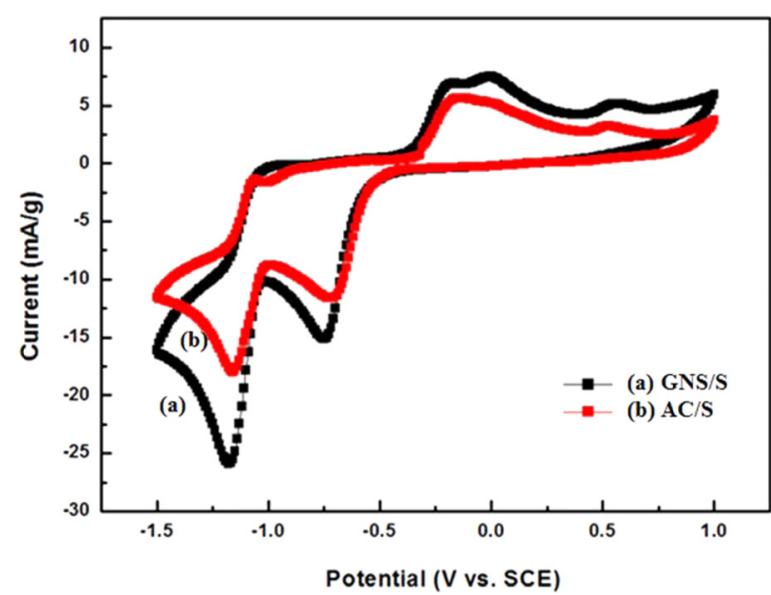

Fig. 5. Cyclic voltammetry curves of the activated carbon/sulfur (AC/S) and graphene nanosheet/sulfur (GNS/S) composites. SCE: saturated calomel electrode.

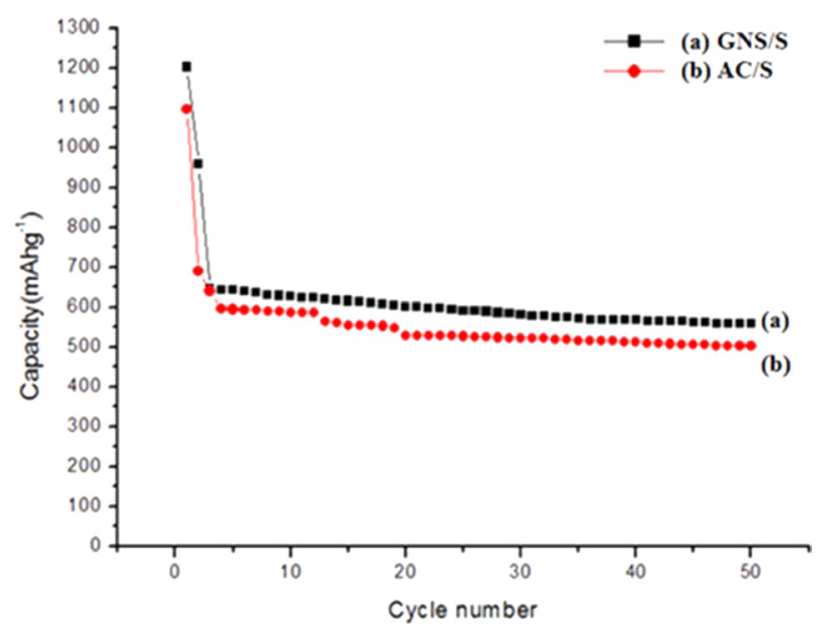

Fig. 6. Cycling performance of activated carbon/sulfur (AC/S) and graphene nanosheet/sulfur (GNS/S) composites.

during the first cathodic-reduction process, two peaks (at about -0.5 and $-1.0 \mathrm{~V}$ ) were observed. The oxidative peak between -0.2 and $0.4 \mathrm{~V}$ indicated a lower-ordered polysulfide (e.g., $\mathrm{S}_{8}$ to $\mathrm{Li}_{2} \mathrm{~S}_{8}$ process). At first, higher-ordered poly-sulfides were indicated between 0.5 and $-1.0 \mathrm{~V}$ (such as $\operatorname{Li}_{2} \mathrm{~S}_{\mathrm{x}}, 1 \leq \mathrm{x} \leq 4$ ), and later, higher-ordered poly-sulfides were indicated between -1.0 and $-1.5 \mathrm{~V}$ (such as $\mathrm{Li}_{2} \mathrm{~S}_{\mathrm{x}}, 4 \leq \mathrm{x} \leq 8$ ).

Fig. 6 shows the discharge capacity versus cycle number of the GNS/S and AC/S composites. The GNS/S contains $20 \mathrm{wt} \%$ sulfur. It was found that the initial discharge capacity of the GNS/S and AC/S composites were 1100 and $1211 \mathrm{mAh} \mathrm{g}^{-1}$, respectively, at a current density of $50 \mathrm{~mA} \mathrm{~g}^{-1}$.

The initial capacity of the GNS/S electrode was higher than that of the AC/S electrode. Furthermore, the cycling stability of the GNS/S composite was also improved. The improvement in the capacity and cycling stability of the electrode with the GNS/S composite electrode may be because the graphene in the composite improved the conductivity of the electrode. 


\section{Conclusion}

In this study, GNS/S and $\mathrm{AC} / \mathrm{S}$ composites was prepared using the infiltration method with organic solvent. Using organic solvent enabled high capacity because it allowed uniform distribution of the melted sulfur on the carbon-materials. Also, by comparing carbon materials with GNS, which has higher conductivity than $\mathrm{AC}$, we concluded that the electrochemical property of the sulfurcontaining GNS electrode had been improved due to the fact that the graphene has higher conductivity and better dispersion. This enabled an increase in the effective surface area of the composite electrode. The graphene-sulfur composite cathodes show excellent electrochemical performance with high specific capacity and good stability in performance, compared to the activated carbon-sulfur composite. These results demonstrate that these GNS/S cathodes are promising candidates for lithium-sulfur cells.

\section{Acknowledgments}

This research was partly supported by the Basic Science Research Program through the National Research Foundation of Korea (NRF-2011-0009007); funded by the Ministry of Science, ICT and Future Planning, Korea. This work was partly supported by the next-generation secondary battery R\&D program of the Ministry of Knowledge and Economy/Korea Evaluation Institute of Industrial Technology (Grant No. 10042575.2012). This work was also supported by the BK21 Plus Program for Advanced Chemical Technology, Korea.

\section{References}

[1] Li K, Wang B, Su D, Park J, Ahn H, Wang G. Enhance electrochemical performance of lithium sulfur battery through a solutionbased processing technique. J Power Sources, 202, 389 (2012). http://dx.doi.org/10.1016/j.jpowsour.2011.11.073.

[2] Kolosnitsyn VS, Karaseva EV. Lithium-sulfur batteries: problems and solutions. Russ J Electrochem, 44, 506 (2008). http://dx.doi. org $/ 10.1134 / \mathrm{S} 1023193508050029$.

[3] Elazari R, Salitra G, Garsuch A, Panchenko A, Aurbach D. Sulfurimpregnated activated carbon fiber cloth as a binder-free cathode for rechargeable li-s batteries. Adv Mater, 23, 5641 (2011). http:// dx.doi.org/10.1002/adma.201103274.

[4] Oh MS, Kim S. Effect of dodecyl benzene sulfonic acid on the preparation of polyaniline/activated carbon composites by in situ emulsion polymerization. Electrochim Acta, 59, 196 (2012). http:/ dx.doi.org/10.1016/j.electacta.2011.10.058.

[5] Choi YJ, Chung YD, Baek CY, Kim KW, Ahn HJ, Ahn JH. Effects of carbon coating on the electrochemical properties of sulfur cathode for lithium/sulfur cell. J Power Sources, 184, 584 (2008). http://dx.doi.org/10.1016/j.jpowsour.2008.02.053

[6] Oh MS, Kim S. Preparation and electrochemical characterization of polyaniline/activated carbon composites as an electrode materials for supercapacitors. J NanoSci Nanotechnol, 12, 519 (2012). http://dx.doi.org/10.1166/jnn.2012.5337.

[7] Song JY, Wang YY, Wan CC. Review of gel-type polymer electrolytes for lithium-ion batteries. J Power Sources, 77, 183 (1999).
http://dx.doi.org/10.1016/S0378-7753(98)00193-1.

[8] Scrosati B, Garche J. Lithium batteries: status, prospects and future. J Power Sources, 195, 2419 (2010). http://dx.doi.org/10.1016/j. jpowsour.2009.11.048.

[9] Ryu HS, Guo ZP, Ahn HJ, Cho GB, Liu HK. Investigation of discharge reaction mechanism of lithium|liquid electrolyte|sulfur battery. J Power Sources, 189, 1179 (2009). http://dx.doi.org/ 10.1016/j.jpowsour.2008.12.073.

[10] Schuster J, He G, Mandlmeier B, Yim T, Lee KT, Bein T, Nazar LF. Spherical ordered mesoporous carbon nanoparticles with high porosity for lithium-sulfur batteries. Angew Chem Int Ed, 51, 3591 (2012). http://dx.doi.org/10.1002/anie.201107817

[11] Lai C, Gao XP, Zhang B, Yan TY, Zhou Z. Synthesis and electrochemical performance of sulfur/highly porous carbon composites. J Phys Chem C, 113, 4712 (2009). http://dx.doi.org/10.1021/ jp809473e.

[12] Zhang B, Qin X, Li GR, Gao XP. Enhancement of long stability of sulfur cathode by encapsulating sulfur into micropores of carbon spheres. Energy Environ Sci, 3, 1531 (2010). http://dx.doi. org/10.1039/C002639E.

[13] Jayaprakash N, Shen J, Moganty SS, Corona A, Archer LA. Porous hollow carbon@sulfur composites for high-power lithiumsulfur batteries. Angew Chem, 123, 6026 (2011). http://dx.doi. org/10.1002/ange.201100637.

[14] Yan J, Wei T, Shao B, Fan Z, Qian W, Zhang M, Wei F. Preparation of a graphene nanosheet/polyaniline composite with high specific capacitance. Carbon, 48, 487 (2010). http://dx.doi.org/10.1016/j. carbon.2009.09.066

[15] Zhang C, Wu HB, Yuan C, Guo Z, Lou XW. Confining sulfur in double-shelled hollow carbon spheres for lithium-sulfur batteries. Angew Chem, 124, 9730 (2012). http://dx.doi.org/10.1002/ ange. 201205292.

[16] Guo JC, Xu YH, Wang CS. Sulfur-impregnated disordered carbon nanotubes cathode for lithium-sulfur batteries. Nano Lett, 11, 4288 (2011). http://dx.doi.org/10.1021/n1202297p.

[17] Wang H, Yang Y, Liang Y, Robinson JT, Li Y, Jackson A, Cui Y, Dai H. Graphene-wrapped sulfur particles as a rechargeable lithium-sulfur battery cathode material with high capacity and cycling stability. Nano Lett, 11, 2644 (2011). http://dx.doi.org/10.1021/nl200658a.

[18] Cao Y, Li X, Aksay IA, Lemmon J, Nie Z, Yang Z, Liu J. Sandwich-type functionalized graphene sheet-sulfur nanocomposite for rechargeable lithium batteries. Phys Chem Chem Phys, 13, 7660 (2011). http://dx.doi.org/10.1039/C0CP02477E.

[19] Huang JQ, Liu XF, Zhang Q, Chen CM, Zhao MQ, Zhang SM, Zhu W, Qian WZ, Wei F. Entrapment of sulfur in hierarchical porous graphene for lithium-sulfur batteries with high rate performance from -40 to $60^{\circ} \mathrm{C}$. Nano Energy, 2, 314 (2013). http://dx.doi. org/10.1016/j.nanoen.2012.10.003.

[20] Hummers WS, Offeman RE. Preparation of graphitic oxide. J Am Chem Soc, 80, 1339 (1958). http://dx.doi.org/10.1021/ ja01539a017.

[21] Kim DY, Park SJ, Jung YJ, Kim S. Electrochemical characterization of activated carbon-sulfur composite electrode in organic electrolyte solution. Carbon Lett, 14, 126 (2013). http://dx.doi. org/10.5714/CL.2013.14.2.126.

[22] Zhao MQ, Liu XF, Zhang Q, Tian GL, Huang JQ, Zhu W, Wei F. Graphene/single-walled carbon nanotube hybrids: one-step catalytic growth and applications for high-rate $\mathrm{Li}-\mathrm{S}$ batteries. ACS Nano, 6, 10759 (2012). http://dx.doi.org/10.1021/nn304037d. 